\title{
BIBECHANA
}

A Multidisciplinary Journal of Science, Technology and Mathematics ISSN 2091-0762 (Print), 2382-5340 (Online)

Journal homepage: http://nepjol.info/index.php/BIBECHANA

Publisher: Research Council of Science and Technology, Biratnagar, Nepal

\section{Micellisation behavior on the dodecyltrimethylammonium bromide in the presence of Brij-35 in pure water by conductivity measurement}

\author{
Neelam Shahi, Ajaya Bhattarai* \\ Department of Chemistry, M.M.A.M.C., Tribhuvan University, Biratnagar, Nepal. \\ *E-mail: bkajaya@yahoo.com
}

Article history: Accepted 28 November, 2017

DOI: http://dx.doi.org/10.3126/bibechana.v15i0.18443

This work is licensed under the Creative Commons CC BY-NC License. https://creativecommons.org/licenses/bync/4.0/

\begin{abstract}
Conductivity measurement of dodecyltrimethylammonium bromide in the presence of Brij-35 in aqueous media at $289.15 \mathrm{~K}$ is performed. The result showed a sharp increase in conductivity with increase in the concentration of dodecyltrimethylammonium bromide in the presence of Brij-35. The graph of specific conductivity versus concentration is used in determining the critical micelle concentration (CMC). There is the decrease in $\mathrm{CMC}$ of dodecyltrimethylammonium bromide in the presence of Brij-35 in comparison with the CMC of dodecyltrimethyl ammonium bromide [DTAB]. Gibbs free energy of micellisation has also been evaluated.
\end{abstract}

Keywords: Dodecyltrimethylammonium bromide; Brij-35; Conductivity; Critical micelle concentration.

\section{Introduction}

Critical micelle concentrations have been experimentally determined using a number of different methodologies [1,2]. The critical micellar concentration of surfactant in pure water is determined by conductometry method by plotting specific conductance versus surfactant concentration. The data points above and below the inflation were fitted to two linear equation and the curves were obtained from the common intersection. The resolution of $\mathrm{CMC}$ indicates self-aggregation of amphiphilic molecules in aqueous media. The idea of CMC plays the significant role during scientific research [3-5].

DTAB is a quaternary ammonium cationic surfactant. It has been used in a study assess the distribution of binary mixed counter ions in surfactant adsorbed films. Brij-35 is a non-ionic surfactant which is beneficial in UV monitoring of solubilized proteins due to their low UV absorbance. It is a polyglycol ether which functions as a detergent for the isolation of functional cell membrane complexes. Different investigation clarifies that Brij-35 acts as a surfactant in Micellar electrokinetic Chromatography(MEKC). 
It is beneficial in slowing down electroosmotic pump which allows users to change $\mathrm{pH}$ values without drastically altering the flow rate. The optimization of mixtures of surfactants in aqueous solution is an important part of the formulation of many commercial cleaning products [6]. The mixture of ionic and non-ionic surfactants in pure water exhibit the highly non-ideal behaviour and their behaviour can be complementary to the mixed micelle causing the CMC to decrease [7].

Cationic surfactants are used as antifungal, antibacterial and antiseptic agents and have attracted recently more attention with reference to their DNA and lipids whereas non-ionic surfactants are useful as detergents, solubilizers and emulsifiers [8,9].

There are many examples in the literature showing that binary mixtures of different types of surfactant are non-ideal in such a way that important properties of the mixture are quite different from those of the individual species [10-12]. In the literature, it is possible to find data concerning the anionic/non-ionic mixtures of two surfaces rather than those of cationic/non-ionic surfactants [2].

\section{Experimental}

DTAB and Brij-35 (Merck Specialties Pvt. Ltd., Mumbai, India) were dried in an electric oven below their melting points for $1 \mathrm{~h}$ and $0.00124 \mathrm{M}$ Brij-35 solution was prepared by dissolving $0.3715 \mathrm{gm}$ in 250 $\mathrm{ml}$ volumetric flask. $0.0748 \mathrm{M}$ DTAB solution was prepared by dissolving $2.3051 \mathrm{gm}$ in $100 \mathrm{ml}$ volumetric flask by using Brij 35 solution and $25 \mathrm{ml}$ DTAB solution in the presence of Brij-35 was taken in a small beaker and specific conductance was measured using conductivity meter (LT-17 E.I. an ISO 9001-2000 certified company).

Further reading of specific conductance was measured by the process of internal dilution [25 ml DTAB $2 \mathrm{ml} \mathrm{DTAB}=23 \mathrm{ml}$ DTAB and adding $2 \mathrm{ml}$ Brij-35 solution making $25 \mathrm{ml}$ DTAB + Brij-35 solution] repeating a process no. of times till the constant reading appeared.

Thus, the graph was plotted taking specific conductance vs concentration of the surfactant so that CMC was determined.

\section{Results and Discussion}

The specific conductance of DTAB in the presence of Brij -35 solution at different concentrations was mentioned in table 1 .

The CMC determined using conductivity method is the most reliable and easy method for the investigation. The CMC value obtained for the mixed surfactant (cationic and non-ionic surfactant) in pure water has the significant influence on the CMC value in contrast to the single cationic surfactant. The size and type of structure of the polar head region of the surfactant molecule play a significant role in surfactant's CMC under different conditions.

Small ionic heads typically form micelles at higher molar concentrations than surfactants with large nonionic compounds. Thus the mixed cationic and non-ionic surfactant have decreased CMC value than single cationic surfactant due to their non-ideal behaviour. Thus, the CMC of mixed surfactants in pure water was determined using conductivity method at temperature $289.15 \mathrm{~K}$. The CMC determined is 12.42 mmol/lt obtained from the break in the conductance-concentration profile (Fig.1).

There is the intersection of two lines having different slopes is identified as CMC. The ratio of slopes i.e., post-micellar slope $\left(S_{2}\right)$ to the pre-micellar slope $\left(S_{1}\right)$ gives the degree of ionization $(\alpha)$.

$\alpha=S_{2} / S_{1}$ 
Table 1: Variation of specific conductance versus concentration of DTAB in the presence of Brij-35.

\begin{tabular}{|l|c|c|c|}
\hline S.No. & Volume of (DTAB+Brij 35) ml & $\begin{array}{l}\text { Specific } \\
\text { Conductance }(\mathrm{ms} / \mathrm{cm})\end{array}$ & Concentration(mol/lt) \\
\hline 1 & 25 & 1.46 & 0.0322 \\
\hline 2 & 25 & 1.39 & 0.0298 \\
\hline 3 & 25 & 1.32 & 0.0274 \\
\hline 4 & 25 & 1.26 & 0.0254 \\
\hline 5 & 25 & 1.20 & 0.0234 \\
\hline 6 & 25 & 1.14 & 0.0213 \\
\hline 7 & 25 & 1.08 & 0.0197 \\
\hline 8 & 25 & 1.04 & 0.0181 \\
\hline 9 & 25 & 1.00 & 0.0167 \\
\hline 10 & 25 & 0.97 & 0.0153 \\
\hline 11 & 25 & 0.93 & 0.0141 \\
\hline 12 & 25 & 0.89 & 0.0130 \\
\hline 13 & 25 & 0.85 & 0.0119 \\
\hline 14 & 25 & 0.81 & 0.0110 \\
\hline 15 & 25 & 0.77 & 0.0101 \\
\hline 16 & 25 & 0.73 & 0.0092 \\
\hline 17 & 25 & 0.67 & 0.0081 \\
\hline 18 & 25 & 0.63 & 0.0072 \\
\hline 19 & 25 & 0.57 & 0.0060 \\
\hline 20 & 25 & 0.53 & 0.0052 \\
\hline
\end{tabular}

The CMC value has been calculated for DTAB in pure water is $12.68 \mathrm{mmol} / \mathrm{lt}$. It is seen that the CMC value has been decreased in the mixture of cationic and non-ionic surfactant in pure water than the CMC value of cationic surfactant in pure water.

On the basis of pseudo-phase separation model [13], standard Gibb's free energy of micellization $\left(\Delta G_{\mathrm{m}}^{\mathrm{o}}\right)$ is calculated from the relation

$\Delta G_{\mathrm{m}}^{\mathrm{o}}=(2-\alpha) R T \ln X_{\mathrm{CMC}}$

where $R$ is universal gas constant, $T$ is the temperature and $X_{\mathrm{CMC}}$ is mole fraction of surfactant at CMC.

The critical micelle concentration (CMC) of a surfactant is an important physical parameter. When surfactants are present at the concentration above the CMC they can act as emulsifiers, allowing normally immiscible compounds to dissolve in the solvent [1].

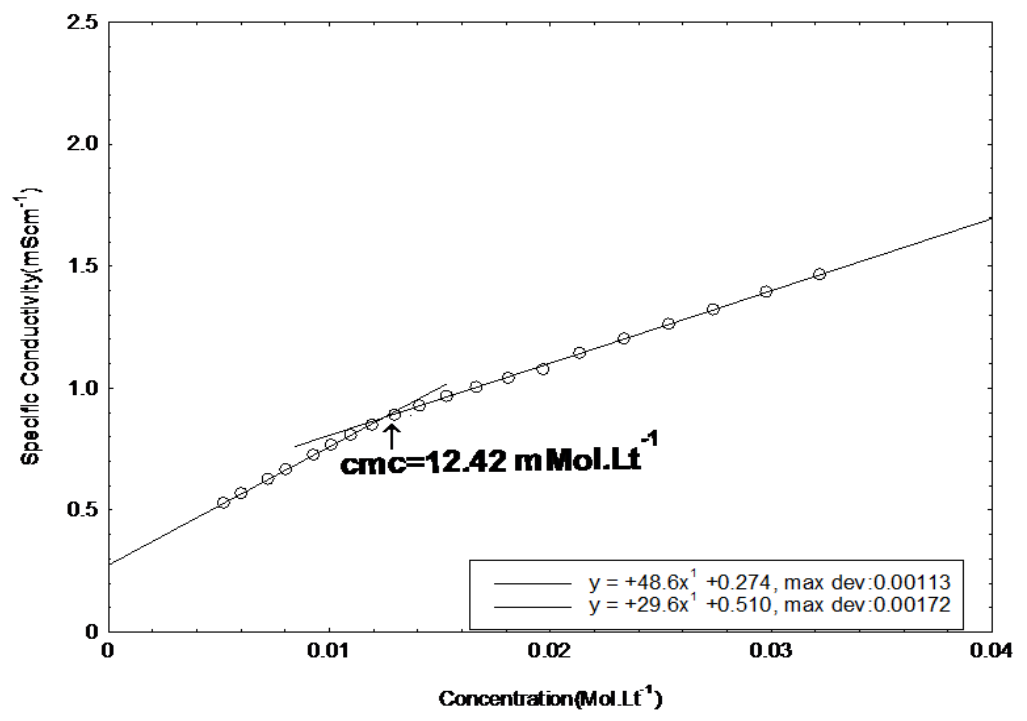

Fig1:Variation of specific conductivity versus concentration of DTAB in the presence of Brij-35. 
The normally insoluble compound is sequestered in the micelle core, while the head group interacts with the solvent. The CMC value of the mixed surfactants is significantly necessary for further utilization in different modern methods. Among them, conductometry method has been adopted for CMC determination for the mixed surfactants. This method is found to be reliable and convenient for the present system because of the significant variations of specific conductivity with surfactant concentration in the pre- and post-micellar regions which allowed us to draw two unambiguous straight lines above and below the CMC.

It is the matter of great concern for further investigation under such mixed surfactant in characterized solvent media for better utilization. The Gibbs free energy of micellisation of dodecyltrimethylammonium bromide in the presence of Brij-35 is found to be $-28.96 \mathrm{~kJ} / \mathrm{mol}$. According to Sharma et.al [2], $\Delta G_{\mathrm{m}}$ value of the mixed cationic (TTAB) and non-ionic (Brij-35) surfactants were obtained from Phase separation model and also by Maeda's method [14]. Mukherjee et. al [14] explained that difference in chain length between surfactants brings stability in the micelle causing interaction between chains. Mukherjee et al [15] proposed the "Contact hydrophobic interaction" in the mixed micelle in the mixture of surfactants. In the present study, DTAB constitutes 15 carbons but in Brij-35 with 58 carbon atoms are present in their respective hydrocarbon chain.

\section{Conclusion}

The following conclusions have been drawn from above results and discussion. The specific conductivities are found to increase with the increase in the concentration of DTAB in the presence of Brij-35 whereas the CMC of DTAB in the presence of Brij-35 decreases in comparison with the CMC determined for cationic surfactant (DTAB). This study reveals for the determination of CMC value for cationic in the presence of non-ionic surfactants which is significant for commercial utilization and scientific interest. The negative value of Gibbs free of micellisation has been evaluated.

\section{Acknowledgment}

One of the authors (Neelam Shahi) is very grateful to Associate Prof. Sitaram Gupta (Head of the Department of Chemistry), Mahendra Morang Adarsh Multiple Campus for providing research facilities.

\section{References}

[1] M. Prasad, R. Palepu, S. P. Moulik, Interaction between sodium dodecyl sulfate (SDS) and polyvinylpyrrolidone (PVP) investigated with forward and reverse component addition protocols employing tensiometric, conductometric, microcalorimetric, electrokinetic, and DLS techniques. Colloid Polym. Sci. 284 (2006 ) 871-878. doi.org/10.1007/s00396-005-1453-8.

[2] K.S.Sharma, S. R. Patil, A.K. Rakshit, Self-aggregation of a cationic-nonionic surfactant mixture in aqueous media: Tensiometric, conductometric, density, light scattering, potentiometric, and fluorometric studies. J. Phys. Chem. B 108 (2004) 12804-12812. doi.org/10.1021/jp048294o.

[3] J.D. Hines, R.K. Thomas, P.R.Garrett, G.K. Rennie, J.Penfold, Investigation of mixing in binary surfactant solutions by surface tension and neutron reflection: Anionic/nonionic and zwitterionic/nonionic mixtures. J. Phys. Chem. B 101 ( 1997 ) 9215-9223. doi.org/10.1021/jp972099a.

[4] A. Shiloach, D. Blankschtein, Measurement and prediction of ionic/nonionic mixed micelle formation and growth. Langmuir 14 (1998) 7166-7182. doi.org/10.1021/la980646t.

[5] S.K. Shah, A. Bhattarai, S.K. Chatterjee, Surfactants, its applications and effects on environment. BIBECHANA 7(2011) 61-64. doi.org/10.3126/bibechana.v7i0.4047. 
[6] N. Dubey, A Conductometric study of interaction between sodium dodecyl sulfate and 1-Propanol, 1-Butanol, 1-Pentanol and 1-Hexanol at different temperatures. J. Surface Sci. Technol. 24 (2008)139-148.

[7] B. Jańczuk, J.M. Bruque, M. L. González-Martin, C. Dorado-Calasanz, The properties of mixtures of ionic and nonionic surfactants in water at the water/air interface. Colloids and Surfaces A: Physicochemical and Eng. Aspects 104 (1995) 157-163. doi.org/10.1016/0927-7757(95)03287-0.

[8] P.K. Jana, S.P. Moulik, Interaction of bile salts with hexadecyltrimethylammonium bromide and sodium dodecyl sulfate. J. Phys.Chem. 95 (1991) 9525-9532. doi.org/10.1021/j100176a089.

[9] S.P.Moulik, M.E. Haque, P.K. Jana, A. R. Das, Micellar properties of cationic surfactants in pure and mixed states. J.Phys.Chem. 100(1996)701-708. doi.org/10.1021/jp9506494.

[10] M. Bourrel, D. Bernard, A. Gracra, Properties of binary mixtures of anionic and cationic surfactants: Micellization and Microemulsions. Tenside Deterg. 21(1984) 311-318.

[11] H. Hoffmann, G. Possneeker, The mixing behavior of surfactants. Langmuir 10 (1994) 381-389. doi.org/10.1021/la00014a009.

[12] P.M. Holland, D. N. Rubingh, Nonideal multicomponent mixed micelle model. J. Phys. Chem. 87 (1983)1984-1990. doi.org/10.1021/j100234a030.

[13] T. Perger, M. Bester-Rogac, Thermodynamics of micelle formation of alkyltrimethylammonium chlorides from high performance electric conductivity measurements. J. Colloid Interface Sci. 313 (2007) 288-295. doi.org/10.1016/j.jcis.2007.04.043.

[14] H. Maeda, A simple thermodynamic analysis of the stability of ionic/nonionic mixed micelles. Colloid Interface Sci. 172 (1995) 98-105. doi.org/10.1006/jcis.1995.1230.

[15] P. Mukerjee, Fluorocarbon-hydrocarbon interactions in micelles and other lipid assemblies, at interfaces, and in solutions. Colloids Surf. A 84 (1994) 1-10. doi.org/10.1016/0927-7757(93)02682-5. 